Review

\title{
Bioactive Metabolites and Potential Mycotoxins Produced by Cordyceps Fungi: A Review of Safety
}

\author{
Bo Chen ${ }^{1,2}$, Yanlei Sun ${ }^{1,2}$, Feifei Luo ${ }^{1}$ and Chengshu Wang $1,2,3, * \mathbb{C}$ \\ 1 Key Laboratory of Insect Developmental and Evolutionary Biology, CAS Center for Excellence in Molecular \\ Plant Sciences, Shanghai Institute of Plant Physiology and Ecology, Chinese Academy of Sciences, Shanghai \\ 200032, China; chenbo@sippe.ac.cn (B.C.); sunyanlei@sippe.ac.cn (Y.S.); ffluo@sibs.ac.cn (F.L.) \\ 2 CAS Center for Excellence in Biotic Interactions, University of Chinese Academy of Sciences, \\ Beijing 100049, China \\ 3 School of Life Science and Technology, ShanghaiTech University, Shanghai 201210, China \\ * Correspondence: wangcs@sippe.ac.cn; Tel.: +86-21-549242157
}

Received: 30 May 2020; Accepted: 15 June 2020; Published: 19 June 2020

check for updates

\begin{abstract}
Ascomycete Cordyceps fungi such as C. militaris, C. cicadae, and C. guangdongensis have been mass produced on artificial media either as food supplements or health additives while the byproducts of culture substrates are largely used as animal feed. The safety concerns associated with the daily consumption of Cordyceps fungi or related products are still being debated. On the one hand, the known compounds from these fungi such as adenosine analogs cordycepin and pentostatin have demonstrated different beneficial or pharmaceutical activities but also dose-dependent cytotoxicities, neurological toxicities and or toxicological effects in humans and animals. On the other hand, the possibility of mycotoxin production by Cordyceps fungi has not been completely ruled out. In contrast to a few metabolites identified, an array of biosynthetic gene clusters (BGCs) are encoded in each genome of these fungi with the potential to produce a plethora of as yet unknown secondary metabolites. Conservation analysis of BGCs suggests that mycotoxin analogs of PR-toxin and trichothecenes might be produced by Cordyceps fungi. Future elucidation of the compounds produced by these functionally unknown BGCs, and in-depth assessments of metabolite bioactivity and chemical safety, will not only facilitate the safe use of Cordyceps fungi as human food or alternative medicine, but will also benefit the use of mass production byproducts as animal feed. To corroborate the long record of use as a traditional medicine, future efforts will also benefit the exploration of Cordyceps fungi for pharmaceutical purposes.
\end{abstract}

Keywords: Cordyceps fungi; mass production; mycotoxins; biosynthetic gene cluster; toxicity; safety

Key Contribution: A few species of Cordyceps fungi have been used as traditional medicines for a long time. These fungi can now be mass-produced at magnitudes from dozens to thousands of tons a year in Asian countries. Based on the known compounds and putative mycotoxins that might be produced by these fungi; safety assessments and future efforts are still required to alleviate concerns when consuming these fungi as food supplements or health additives and using the related byproducts as animal feed.

\section{Introduction}

Filamentous fungi are rich producers of bioactive secondary metabolites, some of which either have been developed as commercial drugs to save lives or are carcinogenic or neurotoxic mycotoxins that threaten human health [1]. The production of these compounds has long been considered to be dispensable for fungal biology since the disruption of the biosynthetic gene clusters (BGCs) 
could barely, if at all, impair fungal growth and development under experimental conditions [2]. However, many studies have shown that the small molecules produced by fungi play essential roles in fungus-environment interactions $[3,4]$. For example, metabolites with antibiotic and antifungal activities are used by the producing fungi to outcompete other microbes $[5,6]$. The phytotoxins produced by plant pathogens are required in mediating fungus-plant interactions [7], and insecticidal toxins biosynthesized by insect pathogens facilitate fungal infection of insect hosts [8,9]. In addition, the mycotoxins produced by plant pathogens or endophytes can frequently result in toxic effects at different levels in herbivorous animals [10], which has been considered as a strategy employed by plants against grazers [11]. Thus, small molecules produced by fungi are of biological importance to producers and beyond.

In nature, there are more than 1000 species of fungi that can infect and kill insects, most of which are ascomycete entomopathogenic fungi [12]. In particular, three families of Hypocrealean fungi, i.e., Cordycipitaceae, Ophiocordycipitaceae, and Clavicipitaceae, contain species that have been used either for biocontrol of insect pests or as Traditional Chinese Medicine (TCM) in Asian countries and beyond [13,14]. For example, the species of Ophiocordyceps sinensis, Cordyceps militaris, and C. cicadae (syn. Isaria cicadae) have been used as TCM with recorded antibiotic, anti-inflammatory, anti-aging, anti-cancer, anti-proliferative, anti-metastatic, anti-fatigue, and immunomodulatory activities or effects (Table 1) for a long time in history $[15,16]$. On the other hand, similar to other traditional herbs, the safety of consuming these fungi has long been a concern [16]. A plethora of bioactive metabolites have been identified from Hypocrealean entomopathogens $[14,17,18]$, including those which have been developed as commercial drugs such as the immunosuppressant drug cyclosporin A, a cyclodepsipeptide isolated from the Ophiocordycipitaceae fungus Tolypocladium inflatum [6] and the anti-leukemia drug pentostatin, first isolated from Streptomyces, found in C. militaris [19]. Apart from the medicinal or beneficial effects reported for the chemicals identified from Cordyceps fungi, side effects of cytotoxicity and or neurological toxicity have also been reported for these compounds (Table 1). Anecdotal records of nausea, diarrhea and even excessive post-extraction bleeding have been reported after daily consumption of Cordyceps fruiting bodies or related products [20,21]. Thus, in-depth safety evaluation is still required before consuming these fungi.

Table 1. Summary of the reported bioactivity and toxicity of the compounds identified from Cordyceps fungi.

\begin{tabular}{|c|c|c|c|}
\hline Compound & Producing Fungus & Bioactivities & Toxic Effect \\
\hline Cordycepin & $\begin{array}{l}\text { C. militaris; } \\
\text { C. kyusyuensis }\end{array}$ & $\begin{array}{l}\text { Anticancer, anti- inflammatory, } \\
\text { antioxidant, inhibition of RNA } \\
\text { synthesis, insecticidal, antibiotic, } \\
\text { antifungal, antivirus }\end{array}$ & $\begin{array}{c}\text { Gastrointestinal toxicity, bone } \\
\text { marrow toxicity, decrease in } \\
\text { toxicity }\end{array}$ \\
\hline Pentostatin & C. militaris & $\begin{array}{l}\text { Immunosuppressive, inhibitor of } \\
\text { adenosine deaminase, antineoplastic }\end{array}$ & $\begin{array}{c}\text { Nausea, diarrhea, renal and } \\
\text { neurological toxicities, } \\
\text { pulmonary toxicity, } \\
\text { gastrointestinal toxicity }\end{array}$ \\
\hline $\begin{array}{l}\text { N6-(2-Hydroxy- } \\
\text { ethyl)-adenosine }\end{array}$ & $\begin{array}{l}\text { C. militaris; } \\
\text { C. cicadae }\end{array}$ & $\begin{array}{l}\text { Renal protection, anti-cancer, } \\
\text { insecticidal }\end{array}$ & Induction of oxidative stress \\
\hline Tenellin & C. bassiana & $\begin{array}{l}\text { Iron chelation, inhibitor of membrane } \\
\text { ATPase }\end{array}$ & Toxic towards erythrocytes \\
\hline Militarinones & C. militaris & Antimicrobial & Cytotoxicity \\
\hline Fumosorinone & C. fumosorosea & $\begin{array}{l}\text { Inhibitor of tyrosine phosphatase } 1 \mathrm{~B}, \\
\text { activation of insulin pathway, } \\
\text { anti-diabetic }\end{array}$ & / \\
\hline Farinosones & C. farinosa & Neuritotrophic activity & Cytotoxicity \\
\hline Oosporein & $\begin{array}{l}\text { C. cicadae; } \\
\text { C. bassiana }\end{array}$ & $\begin{array}{l}\text { Immunosuppressive, antimicrobial, } \\
\text { metal detoxification }\end{array}$ & Cytotoxicity \\
\hline
\end{tabular}


Table 1. Cont.

\begin{tabular}{cccc}
\hline Compound & Producing Fungus & Bioactivities & Toxic Effect \\
\hline Beauveriolides & $\begin{array}{l}\text { C. militaris; } \\
\text { C. bassiana }\end{array}$ & $\begin{array}{c}\text { Anti-aging, beta-amyloid lowering, } \\
\text { anti-atherogenic }\end{array}$ & Cytotoxicity \\
\hline Beauvericin & $\begin{array}{l}\text { C. cicadae; } \\
\text { C. bassiana }\end{array}$ & $\begin{array}{c}\text { Insecticidal, nematicidal, induction of } \\
\text { cell apoptosis, ionophoric property }\end{array}$ & Cytotoxicity \\
\hline Cordyceamides & O. sinensis & $/$ & Cytotoxicity \\
\hline Cordycedipeptide & O. sinensis & $/$ & Cytotoxicity \\
\hline Cordysinins & O. sinensis & Anti-inflammatory & $/$ \\
\hline
\end{tabular}

Cordyceps fungi are being mass produced for harvesting the fruiting bodies for food and health additives while the byproducts (largely culture substrates) of mass production are then mostly used as animal feed [22]. To alleviate the safety concerns for both purposes, this paper reviews the production and biological activity/toxicity of known metabolites identified from Cordyceps fungi and unknown metabolites deduced from the conserved biosynthetic gene clusters (BGCs) by comparative analysis with those BGCs involved in producing known mycotoxins based on the obtained genome information of these fungi [23-25]. The content of literature reviews conducted in the paper may benefit the future exploration and safety assessment of Cordyceps fungi and their related byproducts used for food, traditional medicine or animal feed.

\section{Mass Production of Cordyceps Fungi}

Ascomycete entomopathogenic fungi are facultative with saprophytic growth abilities. However, it is still technically challenging, often difficult, to induce fungal sexual fruiting bodies on artificial media or on insect hosts under laboratory conditions [26]. Until recently, induction of the fruiting-body formation of the caterpillar fungus $O$. sinensis (best known as $C$. sinensis, one of the most expensive traditional medicines) was not successful $[27,28]$. After inoculation of the ghost moth (Hepialus spp.) larvae, it is an energy-intensive process for fungal infection and development within the insect body cavity at a relatively low temperature (less than $18^{\circ} \mathrm{C}$ ) and the formation of fruiting bodies for a total period of more than half a year (Figure 1A). Dozens of tons of the fruiting bodies (attached with insect cadavers) can now be produced annually in China [28]. In contrast, mass production of C. militaris has long been successful by inoculation of fungal propagates on artificial media (e.g., rice medium) (Figure 1B). Different from the homothallic nature of O. sinensis [26], C. militaris is sexually heterothallic but its single mating-type can also fruit but without mating and meiosis to produce sexual perithecia [29]. Without considering the mass production of C. militaris in Japan, South Korea and Vietnam, the annual yield of the dried fruiting bodies reaches up to 10,000 tons per year in China [22]. The fruiting bodies of $C$. cicadae together with the mycosed cicada pupae have also been used as a TCM in renal protection or for the treatment of chronic kidney disease [23]. Mass production of this fungus has also been successful with a yield of hundreds of tons each year (Figure 1C). In contrast to C. militaris, asexual fruiting bodies, i.e., synnema-like structures, are largely produced by C. cicadae [23]. A few other species such as C. guangdongensis have also been mass produced at different magnitudes in Asian countries. Without consideration of the liquid fermentations of Cordyceps fungi [22], careful evaluation and safety assessment are still required regarding the (daily) consumption of enormous amounts of fruiting bodies and their related products as foods or health-promoting additives, and utilization of the leftover substrates as animal feed. 

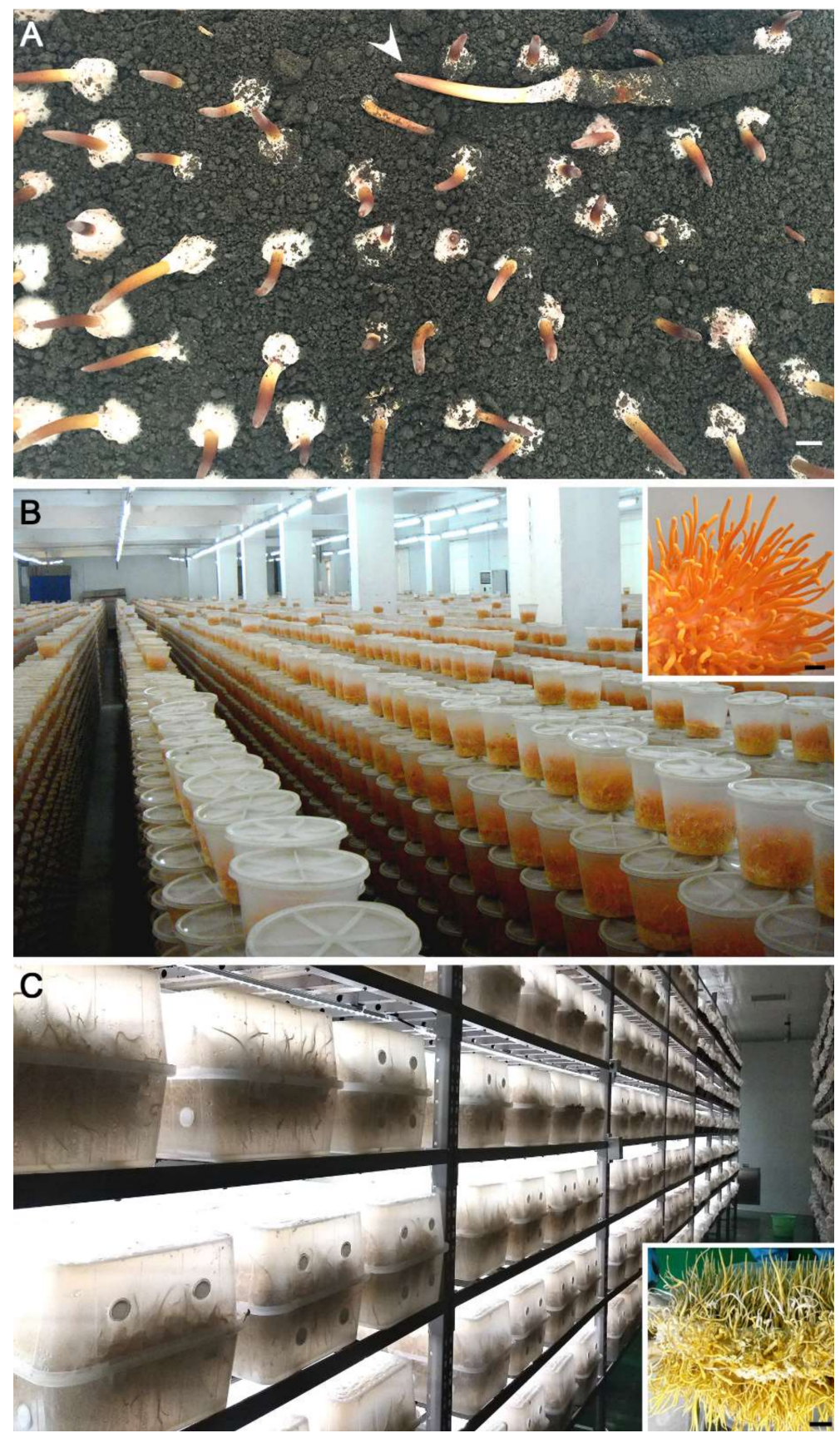

Figure 1. Mass production of Cordyceps fungi. (A) Successful induction of the fruiting bodies (arrowed) of $O$. sinensis after inoculation of the ghost moth larvae for more than 150 days (image taken from the Sunshine Lake LLC, Yichang, China). Bar, $1 \mathrm{~cm}$. (B) Mass production of C. militaris in plastic bottles (image taken from the Honghao Biotech Company, Jiangmeng, China). Insert, the fruiting bodies formed in a bottle 45 days post-inoculation. Bar, $1 \mathrm{~cm}$. (C) Mass production of $C$. cicadae in plastic boxes (image taken from the BioAisa Pharmaceuticals, Pinghu, China). Insert, the fruiting bodies formed in a box 20 days post-inoculation. Bar, $1 \mathrm{~cm}$.

\section{Known Metabolites Produced by Cordyceps Fungi}

Different compounds have been isolated from entomopathogenic fungi including Cordyceps species [17]. One of the most important but arguable metabolites produced by C. militaris is cordycepin, i.e., the adenosine analog 3'-deoxyadenosine (Figure 2). This compound is not produced in O. sinensis and C. cicadae; elucidation of its biosynthetic mechanism showed that the responsible BGC is only present in C. militaris and C. kyusyuensis as well as the evolutionarily distant mold 
fungus Aspergillus nidulans [19]. It was later found that the field-collected samples of O. sinensis, i.e., the complex of fruiting body and insect cadaver, were frequently contaminated with $A$. nidulans and even $C$. militaris that might contribute to the detection of trace amounts of cordycepin in caterpillar fungus [30]. Cordycepin can inhibit RNA synthesis and has demonstrated immense medicinal potential (Table 1), including anti-cancer, anti-inflammatory, antibiotic, anti-virus, and antioxidant activities [31]. However, in addition to its dosage-dependent toxicity to different cells, cordycepin has shown an effect in stimulating testosterone production in the models of both mouse Ledydig cells and mice, which may alter male fertility [32]. Recently, it has been shown that the anti-leukemia drug pentostatin (Figure 2), i.e., the 2'-deoxycoformycin originally isolated from Streptomyces antibioticus being an irreversible inhibitor of adenosine deaminase, can also be produced by $C$. militaris through the same BGC for cordycepin production via a protector-protégé strategy [19]. Similar to other chemotherapeutic drugs/agents, dosage- and schedule-dependent side effects have also been observed for pentostatin that include nausea, diarrhea, and renal and neurological toxicities [33]. The test of cordycepin in combination with pentostatin can trigger severe gastrointestinal toxicity and bone marrow toxicity in dogs [34].<smiles>Nc1ncnc2c1ncn2[C@@H]1O[C@H](CO)C[C@H](O)[C@H]1OC(=O)[O-]</smiles><smiles>CCC(C)/C=C(C)/C=C/C(=O)c1c(O)c(-c2ccc(O)cc2)cn(O)c1=O</smiles>

Tenellin<smiles>CCCC[C@H](C)[C@H]1CC(=O)N[C@H](Cc2ccccc2)C(=O)N[C@H](C)C(=O)N[C@H](CC(C)C)C(=O)O1</smiles>

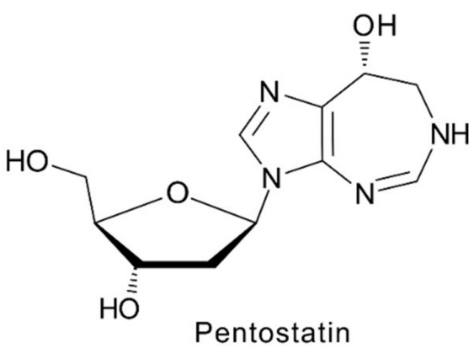<smiles>CC1=C(O)C(=O)C(C2=C(O)C(=O)C(C)=C(O)C2=O)=C(O)C1=O</smiles>

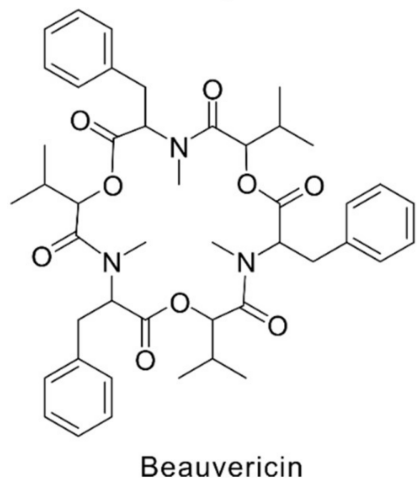

Figure 2. Structure of the selected metabolites identified from Cordyceps fungi.

Apart from cordycepin and pentostatin, another adenosine analog $N^{6}-(2$-Hydroxyethyl)-adenosine (HEA) has been identified in C. cicadae, C. militaris, and other species of Cordyceps with renal protection and anti-cancer activities $[35,36]$. Insecticidal activity of HEA has also been demonstrated by targeting the adenosine receptor (AdoR) of insects [37], suggesting that adenosine analogs can be recognized by AdoR(s) [38]. A different family of AdoRs, the G-protein coupled receptors with seven transmembrane domains, has been identified in humans as potential drug targets [39]. Since adenosine is multifunctional in the physiology of different organisms, the functions of cordycepin and HEA are still unclear, notably 
whether they act as agonists or antagonists of AdoRs in mammals. Deletion of AdoRa1 in mice has led to decreased fertility and an increased risk of seizures [38]. The long-term effect of Cordyceps consumption and the effects of cordycepin and HEA administration on activation or inactivation of AdoRs require further investigation.

Other known metabolites produced by either C. militaris or C. cicadae include 2-pyridone alkaloid tenellin-like compounds and the bibenzoquinone oosporein (Figure 2). Different structures of Tenellin-like pyridones have been identified in different Cordycipitaceae fungi including fumosorinone produced by C. (Isaria) fumosorosea [40], farinosones by I. farinosus [41], and militarinones by C. militaris [42]. These 2-pyridones (Table 1) can maintain iron hemostasis and have also shown profound neuritogenic activity and cell cytotoxicities [42]. Oosporein, originally identified from the insect pathogen Beauveria bassiana (Syn. Cordyceps bassiana), shows insecticidal and antibiotic activities that promote fungal infection of insect hosts $[9,43]$. The conserved gene cluster and production of oosporein has been detected in C. cicadae [23]. This compound can also cause gout in avian species including chickens, turkeys and other birds, and can therefore threaten the safety of the poultry industry if contaminated substrates are used as feed [44].

A few cyclodepsipeptides (Figure 2) have also been identified from Cordyceps fungi, e.g., beauveriolide I and III from C. militaris [45] and beauvericin from C. cicadae [23,46]. Beauveriolides have demonstrated anti-aging [47], beta-amyloid-lowering [48], and anti-atherogenic activity by inhibition of lipid droplet accumulation in macrophages without any obvious side effects [49]. However, insecticidal and nematicidal beauvericin, first isolated from B. bassiana, can induce cytotoxicity and cell apoptosis in a dose-dependent manner due to its ionophoric property that can increase ion permeability in membranes [50]. Overall, along with the beneficial medicinal and or biological activities, different negative effects are also evident with the compounds identified from Cordyceps fungi that raise safety concerns about its consumption.

\section{Unknown Mycotoxins May be Produced by Cordyceps Fungi}

Apart from the metabolites described above, many more can be expected after genomic analysis of Cordyceps fungi that identifies an array of BGCs encoded in each fungus (Figure 3A). For example, eight non-ribosomal peptide synthetase (NRPS), seven polyketide synthase (PKS), five NRPS-PKS and four terpene synthase (TS) BGCs are encoded in the genome of C. militaris [25,51]. Likewise, the BGCs of eight NRPSs, eight PKSs, six NRPS-PKSs and six TSs are encoded in C. cicadae [23]. Consistently, metabolomic analysis also suggested that diverse compounds can be produced by these fungi [23,52]. Due to the frequent occurrence of gene silence of fungal BGCs under experimental conditions [2], many unknown metabolites remain to be determined. Genome-wide phylogenetic, gene cluster content, and core enzyme structure analyses of NRPS, PKS, and NRPS-PKS BGCs suggest that the Cordyceps fungi may not produce carcinogenic mycotoxins such as aflatoxins $[23,25]$. However, our further analysis indicated that the putative aristolochen synthase CCM_03050 is highly similar (65\% identity at amino acid level) to PRX2, and the clustered CCM_03051 is similar to the short chain dehydrogenase (SDR) PRX4 of Penicillium roqueforti involved in PR-toxin production (Figure 3B). The bicyclic sesquiterpene PR-toxin can cause significant damage to liver and kidney, induce abortions and reduce fertility in cattle. However, its derivatives such as PR-acid and PR-imine are largely non-toxic and unstable [53]. The biosynthesis of PR-toxin requires at least four genes, i.e., $\operatorname{Pr} x 1-\operatorname{Pr} x 4$ in P. roqueforti [54]. Considering that the tailoring enzyme genes Prx1 (for a SDR) and Prx3 (for a quinone oxidoreductase) are missing in C. militaris whereas the clustered CCM_03049 encodes a putative dioxygenase/oxygenase and CCM_03052 encodes a cytochrome P450 enzyme, this TS BGC may not biosynthesize PR-toxin but its analog(s) requiring further investigation. Intriguingly, these conserved genes are absent in the genomes of the closely-related C. cicadae and other Cordycipitaceae fungi, based on the survey of their genome contents. 

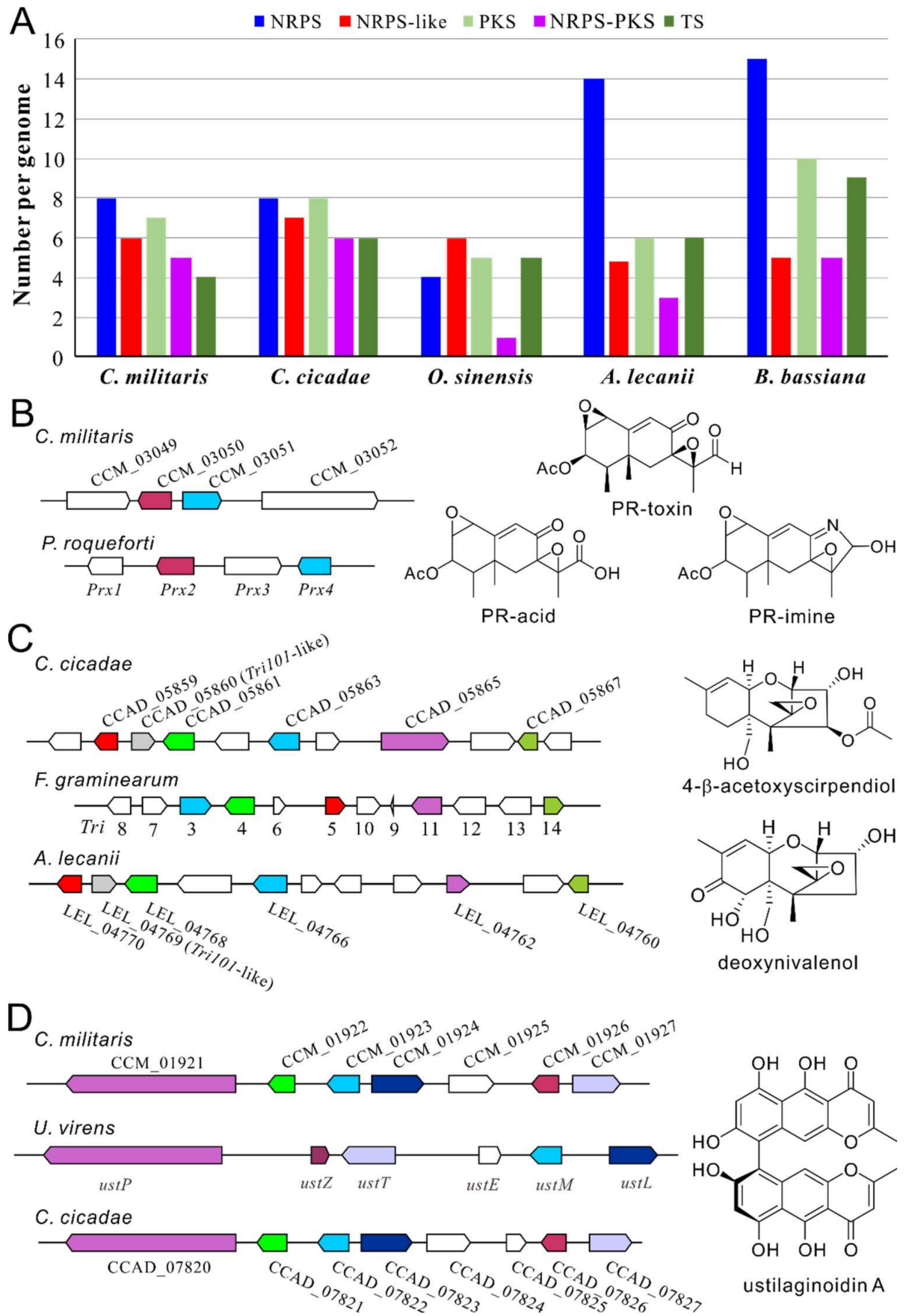

Figure 3. Conservation analysis of the gene clusters between Cordyceps and other fungi involved in toxin production. (A) Comparative analysis of the biosynthetic gene clusters (BGCs) encoded in the genomes of the selected Cordycipitaceae fungi. NRPS, non-ribosomal peptide synthetase; PKS, polyketide synthase; TS, terpene synthase. (B) Conservation between the gene clusters of C. militaris and those of $P$. roqueforti involved in PR-toxin production. (C) Conservation between the gene clusters of the Cordycipitaceae fungi C. cicadae and A. lecanii and that of F. graminearum involved in the biosynthesis of trichothecenes. (D) Conservation between the gene clusters of C. militaris and C. cicadae and that of $U$. virens involved in the production of ustilaginoidins. The genes labeled in the same color within the panels (B-D) represent orthologous relationships. The compound(s) shown in the right of the panels (B-D) indicates the structures of the representative metabolites produced by the known BGCs in the related or reference fungal species. 
We also found that the Cordycipitaceae fungi C. cicadae and Akanthomyces lecanii (anamorph: Lecanicillium lecanii) each encode a gene cluster that shows conservation with the BGC involved in the production of trichothecene (Tri) mycotoxins in wheat head blight Fusarium graminearum (Figure 3C). Phytotoxic trichothecenes are a class of sesquiterpenes that contain more than 150 chemically-related compounds such as type A mycotoxins T-2, HT-2, and NX-2, and type B deoxynivalenol (DON), acetylated DON, and nivalenol toxins that can inhibit protein synthesis and are neurotoxic, immunosuppressive, and nephrotoxic in mammals $[55,56]$. The biosynthesis of trichothecenes has been clarified with the involvement of 15 Tri genes located at three different loci including a 12-gene core cluster, a single gene Tri101 and two genes Tri1 and Tri16 loci on different chromosomes of $F$. graminearum $[57,58]$. We found that the homologs of the core gene Tri5 for trichodiene synthase are conservedly present in C. cicadae (CCAD_05859, 70\% identity) and A. lecanii (LEL_0770, 79\% identity). The homologs of the essential biosynthetic genes Tri3, Tri4, Tri11 and Tri14 are also present in the genomes of these two fungi. In addition, interestingly, the homologs of the isolated gene Tri101 (encoding an acetyltransferase) in F. graminearum are present in the core cluster of Cordyceps fungi, i.e., LEL_04769 (40\% identity) and CCAD_05860 (37\% identity) (Figure 3C). Likewise, the homologs of the isolated gene Tri1 are also present in the separated loci of two fungi (CCAD_02575, 42\% identity; LEL_06734, 41\% identity). Taken together, it is considerably likely that C. cicadae and A. lecanii may produce trichothecene-like mycotoxin(s) that requires clarification and toxicity tests. In support, the trichothecene derivative 4 - $\beta$-acetoxyscirpendiol (4-acetyl-12,13-epoxyl-9-trichothecene-3,15-diol) was once isolated from the fruit-body samples of Isaria japonica (syn. Cordyceps tenuipes) and the compound could induce apoptosis of human leukemia cells [59]. This Tri-like BGC is not present in C. militaris but is present in the closely-related biocontrol fungus B. bassiana (TRI5 vs. BBA_08696, 69\% identity; TRI101 vs. BBA_08697, 41\%) after genome survey [56]. A Tri-like BGC has also been identified in diverse fungal species including Trichoderma spp., which is responsible for the production of the trichothecene derivatives harzianums A and B with antimicrobial activities [60,61].

The bis-naphthopyrone-type pigments are widely produced by different fungi that can protect filamentous fungi from fungivores [62] or abiotic stress factors like UV radiation and high temperatures $[63,64]$. Genome survey indicated that both C. militaris and C. cicadae contain a conserved PKS BGC like that of rice false smut Ustilaginoidea virens (Figure 3D), which is responsible for the production of ustilaginoidins [65]. Different analogs of ustilaginoidins have varied level of antibacterial, cytotoxic, and phytotoxic activities [66]. The exact compound(s) produced by this PKS gene cluster remains to be determined in Cordyceps fungi.

In contrast to other Cordyceps fungi, the caterpillar fungus $O$. sinensis has a highly repetitive genome with a limited number of genes and BGCs (Figure 3A) [24]. Besides the reported bioactive constituents like nucleosides, sterols and polysaccharides [18,67-69], a few compounds have been identified from this fungus with different activities such as the aurantiamides cordyceamides A and B with unclear activity/toxicity [70], the cyclodipeptide cordycedipeptide A with cytotoxicity [71], and the cyclodipeptide cordysinins with antioxidant activity [69,72]. Overall, the reputed health benefits of this fungus are still unclear [73]. Despite the mass production of sexual fruiting bodies being recently successful [74], the slow growing nature of this fungus makes it technically problematic to perform transgenic and chemical genetic investigations [73]. With the help of heterologous expression systems, future efforts can be taken to explore the production, if any, of mycotoxin as well as the pharmaceutical potential of this fungus.

\section{Requirement of Safety Assessments}

As indicated above, toxicological concerns about consuming Cordyceps fungi as food supplements or using their byproducts as animal feed are raised based on the evaluations of either the known compounds they produce or those previously unreported toxins being putatively produced by the conserved BGCs of Cordyceps fungi. Obviously, the production of the avian-gout toxin oosporein by C. cicadae suggests that mass-production byproducts cannot be used as feed for poultry. In particular, 
except for the unknown metabolites biosynthesized by other BGCs, the potential of the production of analogous PR-toxin in C. militaris and Tri-like toxin(s) in C. cicadae raises substantial concerns that require further investigation and safety assessments. Traditionally, instead of using the purified compounds, the fruiting bodies or mycelium samples of Cordyceps fungi were used for direct safety assessments, including bacterial Ames tests, different cell- and/or animal-model tests for mutagenic, clastogenic, genotoxic, and (sub-)accurate toxic effects, which suggested that consumption of Cordyceps fungi might be safe $[75,76]$. However, considering the magnitude of the mass production of Cordyceps fungi in China and other countries, in-depth monitoring and assessment are still required, given the daily consumption of Cordyceps fruiting bodies or related products as tonics or food/health additives and the use of culture substrates as feed. In particular, aside from the feature of culture stability, high titer of cordycepin and pentostatin production is being used as the key standard for screening of $C$. militaris strains for industrial mass production. Consistent with the side effects of pentostatin and adenosine analogs [33,38], the negative effects of nausea and diarrhea have been anecdotally reported by enthusiasts after consuming products with enriched contents of cordycepin/pentostatin [14]. Indeed, it is common and typical that mycotoxin production and accumulation are dependent on the fungal culturing media and stage, and the side effects of daily consumptions are dose- and even consumer-dependent [20]. For example, trichothecene production was not detected in A. lecanii and B. bassiana after inductions in multiple artificial media used for the successful induction of toxin formations in other fungi [56]. It is critical at least that toxin production is clarified for the Cordyceps fungi under mass production conditions.

\section{Conclusions and Prospective}

Along with the increasing level of the mass production of Cordyceps fungi such as C. militaris and C. cicadae, there is increasing consumption of the fruiting bodies or related products as food supplements or health additives, and use of the byproducts as animal feed. To alleviate safety concerns, full elucidation of the BGCs' capacities in production of different compounds is critically needed. In addition to promoting toxicological tests with the known and newly-identified compounds, in-depth investigations may also benefit the exploration of these fungi for pharmaceutical potential.

Author Contributions: Conceptualization, C.W.; methodology, B.C. and C.W.; data curation, B.C., Y.S., F.L., and C.W.; manuscript writing, C.W.; supervision, C.W.; funding acquisition, C.W. All authors have read and agreed to the published version of the manuscript.

Funding: This work was supported by the National Natural Science Foundation of China (31530001) and the Shanghai Academic/Technology Research Leader Program (grant 18XD1404500).

Acknowledgments: The authors thank Chunru Li from BioAsia Pharmaceuticals for provision of the mass production pictures of $C$. cicadae.

Conflicts of Interest: The authors declare no conflict of interest.

\section{References}

1. Marin, S.; Ramos, A.J.; Cano-Sancho, G.; Sanchis, V. Mycotoxins: Occurrence, toxicology, and exposure assessment. Food Chem. Toxicol. 2013, 60, 218-237. [CrossRef] [PubMed]

2. Keller, N.P. Fungal secondary metabolism: Regulation, function and drug discovery. Nat. Rev. Microbiol. 2019, 17, 167-180. [CrossRef] [PubMed]

3. Spiteller, P. Chemical ecology of fungi. Nat. Prod. Rep. 2015, 32, 971-993. [CrossRef] [PubMed]

4. Macheleidt, J.; Mattern, D.J.; Fischer, J.; Netzker, T.; Weber, J.; Schroeckh, V.; Valiante, V.; Brakhage, A.A. Regulation and role of fungal secondary metabolites. Annu. Rev. Genet. 2016, 50, 371-392. [CrossRef] [PubMed]

5. Cray, J.A.; Bell, A.N.; Bhaganna, P.; Mswaka, A.Y.; Timson, D.J.; Hallsworth, J.E. The biology of habitat dominance; can microbes behave as weeds? Microb. Biotechnol. 2013, 6, 453-492. [CrossRef] [PubMed]

6. Yang, X.; Feng, P.; Yin, Y.; Bushley, K.; Spatafora, J.W.; Wang, C. Cyclosporine biosynthesis in Tolypocladium inflatum benefits fungal adaptation to the environment. mBio 2018, 9, e01211-18. [CrossRef] 
7. Perincherry, L.; Lalak-Kańczugowska, J.; Stępień, Ł. Fusarium-produced mycotoxins in plant-pathogen interactions. Toxins 2019, 11, 664. [CrossRef]

8. Rohlfs, M.; Churchill, A.C. Fungal secondary metabolites as modulators of interactions with insects and other arthropods. Fungal Genet. Biol. 2011, 48, 23-34. [CrossRef]

9. Feng, P.; Shang, Y.; Cen, K.; Wang, C. Fungal biosynthesis of the bibenzoquinone oosporein to evade insect immunity. Proc. Natl. Acad. Sci. USA 2015, 112, 11365-11370. [CrossRef]

10. Philippe, G. Lolitrem B and indole diterpene alkaloids produced by endophytic fungi of the genus Epichlö̈ and their toxic effects in livestock. Toxins 2016, 8, 47. [CrossRef]

11. Rohlfs, M. Fungal secondary metabolite dynamics in fungus-grazer interactions: Novel insights and unanswered questions. Front. Microbiol. 2014, 5, 788.

12. Shang, Y.; Feng, P.; Wang, C. Fungi that infect insects: Altering host behavior and beyond. PLoS Pathog. 2015, 11, e1005037. [CrossRef] [PubMed]

13. Wang, C.; Wang, S. Insect pathogenic fungi: Genomics, molecular interactions, and genetic improvements. Annu. Rev. Entomol. 2017, 62, 73-90. [CrossRef] [PubMed]

14. Olatunji, O.J.; Tang, J.; Tola, A.; Auberon, F.; Oluwaniyi, O.; Ouyang, Z. The genus Cordyceps: An extensive review of its traditional uses, phytochemistry and pharmacology. Fitoterapia 2018, 129, 293-316. [CrossRef] [PubMed]

15. Paterson, R.R. Cordyceps: A traditional Chinese medicine and another fungal therapeutic biofactory? Phytochemistry 2008, 69, 1469-1495. [CrossRef]

16. Das, S.K.; Masuda, M.; Sakurai, A.; Sakakibara, M. Medicinal uses of the mushroom Cordyceps militaris: Current state and prospects. Fitoterapia 2010, 81, 961-968. [CrossRef]

17. Zhang, L.; Fasoyin, O.E.; Molnar, I.; Xu, Y. Secondary metabolites from hypocrealean entomopathogenic fungi: Novel bioactive compounds. Nat. Prod. Rep. 2020. [CrossRef]

18. Zhao, J.; Xie, J.; Wang, L.Y.; Li, S.P. Advanced development in chemical analysis of Cordyceps. J. Pharm. Biomed. Anal. 2014, 87, 271-289. [CrossRef]

19. Xia, Y.L.; Luo, F.F.; Shang, Y.F.; Chen, P.L.; Lu, Y.Z.; Wang, C.S. Fungal cordycepin biosynthesis is coupled with the production of the safeguard molecule pentostatin. Cell Chem. Biol. 2017, 24, 1479-1489. [CrossRef]

20. Hatton, M.N.; Desai, K.; Le, D.; Vu, A. Excessive postextraction bleeding associated with Cordyceps sinensis: A case report and review of select traditional medicines used by Vietnamese people living in the United States. Oral Surg. Oral Med. Oral Pathol. Oral Radiol. 2018, 126, 494-500. [CrossRef]

21. Tuli, H.S.; Sandhu, S.S.; Sharma, A.K. Pharmacological and therapeutic potential of Cordyceps with special reference to cordycepin. 3 Biotech. 2014, 4, 1-12. [CrossRef] [PubMed]

22. Dong, C.; Guo, S.; Wang, W.; Liu, X. Cordyceps industry in China. Mycology 2015, 6, 121-129. [CrossRef] [PubMed]

23. Lu, Y.; Luo, F.; Cen, K.; Xiao, G.; Yin, Y.; Li, C.; Li, Z.; Zhan, S.; Zhang, H.; Wang, C. Omics data reveal the unusual asexual-fruiting nature and secondary metabolic potentials of the medicinal fungus Cordyceps cicadae. BMC Genom. 2017, 18, 668. [CrossRef] [PubMed]

24. Hu, X.; Zhang, Y.J.; Xiao, G.H.; Zheng, P.; Xia, Y.L.; Zhang, X.Y.; St Leger, R.J.; Liu, X.Z.; Wang, C.S. Genome survey uncovers the secrets of sex and lifestyle in caterpillar fungus. Chin. Sci. Bull. 2013, 58, 2846-2854. [CrossRef]

25. Zheng, P.; Xia, Y.; Xiao, G.; Xiong, C.; Hu, X.; Zhang, S.; Zheng, H.; Huang, Y.; Zhou, Y.; Wang, S.; et al. Genome sequence of the insect pathogenic fungus Cordyceps militaris, a valued traditional Chinese medicine. Genome Biol. 2011, 12, R116. [CrossRef] [PubMed]

26. Zheng, P.; Xia, Y.L.; Zhang, S.W.; Wang, C.S. Genetics of Cordyceps and related fungi. Appl. Microbiol. Biotechnol. 2013, 97, 2797-2804. [CrossRef]

27. Liu, G.; Han, R.; Cao, L. Artificial cultivation of the Chinese cordyceps from injected ghost moth larvae. Environ. Entomol. 2019, 48, 1088-1094. [CrossRef]

28. Li, X.; Liu, Q.; Li, W.; Li, Q.; Qian, Z.; Liu, X.; Dong, C. A breakthrough in the artificial cultivation of Chinese cordyceps on a large-scale and its impact on science, the economy, and industry. Crit. Rev. Biotechnol. 2019, 39, 181-191. [CrossRef]

29. Lu, Y.; Xia, Y.; Luo, F.; Dong, C.; Wang, C. Functional convergence and divergence of mating-type genes fulfilling in Cordyceps militaris. Fungal Genet. Biol. 2016, 88, 35-43. [CrossRef] 
30. Zhang, S.W.; Cen, K.; Liu, Y.; Zhuo, X.W.; Wang, C.S. Metatranscriptomics analysis of the fruiting caterpillar fungus collected from the Qinghai-Tibetan plateau. Scientia Sinica Vitae 2018, 48, 562-570.

31. Liao, Y.; Ling, J.; Zhang, G.; Liu, F.; Tao, S.; Han, Z.; Chen, S.; Chen, Z.; Le, H. Cordycepin induces cell cycle arrest and apoptosis by inducing DNA damage and up-regulation of p53 in Leukemia cells. Cell Cycle 2015, 14, 761-771. [CrossRef] [PubMed]

32. Qin, P.; Li, X.; Yang, H.; Wang, Z.Y.; Lu, D. Therapeutic potential and biological applications of cordycepin and metabolic mechanisms in cordycepin-producing fungi. Molecules 2019, 24, 2231. [CrossRef] [PubMed]

33. Margolis, J.; Grever, M.R. Pentostatin (Nipent): A review of potential toxicity and its management. Semin. Oncol. 2000, 27, 9-14. [PubMed]

34. Rodman, L.E.; Farnell, D.R.; Coyne, J.M.; Allan, P.W.; Hill, D.L.; Duncan, K.L.; Tomaszewski, J.E.; Smith, A.C.; Page, J.G. Toxicity of cordycepin in combination with the adenosine deaminase inhibitor 2'-deoxycoformycin in beagle dogs. Toxicol. Appl. Pharmacol. 1997, 147, 39-45. [CrossRef] [PubMed]

35. Zheng, R.; Zhu, R.; Li, X.; Li, X.; Shen, L.; Chen, Y.; Zhong, Y.; Deng, Y. N6-(2-Hydroxyethyl) adenosine from Cordyceps cicadae ameliorates renal interstitial fibrosis and prevents inflammation via TGF-beta1/Smad and NF-kappaB signaling pathway. Front. Physiol. 2018, 9, 1229. [CrossRef] [PubMed]

36. Liu, K.; Wang, F.; Wang, W.; Dong, C. Beauveria bassiana: A new N(6)-(2-hydroxyethyl)-adenosine-producing fungus. Mycology 2017, 8, 259-266. [CrossRef]

37. Fang, M.; Chai, Y.; Chen, G.; Wang, H.; Huang, B. N6-(2-Hydroxyethyl)-Adenosine Exhibits Insecticidal Activity against Plutella xylostella via Adenosine Receptors. PLoS ONE 2016, 11, e0162859. [CrossRef]

38. Chen, J.F.; Eltzschig, H.K.; Fredholm, B.B. Adenosine receptors as drug targets-What are the challenges? Nat. Rev. Drug Discov. 2013, 12, 265-286. [CrossRef]

39. Effendi, W.I.; Nagano, T.; Kobayashi, K.; Nishimura, Y. Focusing on Adenosine Receptors as a Potential Targeted Therapy in Human Diseases. Cells 2020, 9, 785. [CrossRef]

40. Liu, L.X.; Zhang, J.; Chen, C.; Teng, J.T.; Wang, C.S.; Luo, D.Q. Structure and biosynthesis of fumosorinone, a new protein tyrosine phosphatase $1 \mathrm{~B}$ inhibitor firstly isolated from the entomogenous fungus Isaria fumosorosea. Fungal Genet. Biol. 2015, 81, 191-200. [CrossRef]

41. Cheng, Y.; Schneider, B.; Riese, U.; Schubert, B.; Li, Z.; Hamburger, M. Farinosones A-C, neurotrophic alkaloidal metabolites from the entomogenous deuteromycete Paecilomyces farinosus. J. Nat. Prod. 2004, 67, 1854-1858. [CrossRef] [PubMed]

42. Schmidt, K.; Riese, U.; Li, Z.; Hamburger, M. Novel tetramic acids and pyridone alkaloids, militarinones B, C, and D, from the insect pathogenic fungus Paecilomyces militaris. J. Nat. Prod. 2003, 66, 378-383. [CrossRef] [PubMed]

43. Fan, Y.; Liu, X.; Keyhani, N.O.; Tang, G.; Pei, Y.; Zhang, W.; Tong, S. Regulatory cascade and biological activity of Beauveria bassiana oosporein that limits bacterial growth after host death. Proc. Natl. Acad. Sci. USA 2017, 114, E1578-E1586. [CrossRef] [PubMed]

44. Pegram, R.A.; Wyatt, R.D. Avian gout caused by oosporein, a mycotoxin produced by Caetomium trilaterale. Poult. Sci. 1981, 60, 2429-2440. [CrossRef] [PubMed]

45. Wang, X.; Gao, Y.L.; Zhang, M.L.; Zhang, H.D.; Huang, J.Z.; Li, L. Genome mining and biosynthesis of the Acyl-CoA: Cholesterol acyltransferase inhibitor beauveriolide I and III in Cordyceps militaris. J. Biotechnol. 2020, 309, 85-91. [CrossRef]

46. Wang, J.-H.; Zhang, Z.-L.; Wang, Y.-Q.; Yang, M.; Wang, C.-H.; Li, X.-W.; Guo, Y.-W. Chemical constituents from mycelia and spores of fungus Cordyceps cicadae. Chin. Herb. Med. 2017, 9, 188-192. [CrossRef]

47. Nakaya, S.; Mizuno, S.; Ishigami, H.; Yamakawa, Y.; Kawagishi, H.; Ushimaru, T. New rapid screening method for anti-aging compounds using budding yeast and identification of beauveriolide I as a potent active compound. Biosci. Biotechnol. Biochem. 2012, 76, 1226-1228. [CrossRef]

48. Witter, D.P.; Chen, Y.; Rogel, J.K.; Boldt, G.E.; Wentworth, P., Jr. The natural products beauveriolide I and III: A new class of beta-amyloid-lowering compounds. ChemBioChem 2009, 10, 1344-1347. [CrossRef]

49. Ohshiro, T.; Kobayashi, K.; Ohba, M.; Matsuda, D.; Rudel, L.L.; Takahashi, T.; Doi, T.; Tomoda, H. Selective inhibition of sterol O-acyltransferase 1 isozyme by beauveriolide III in intact cells. Sci. Rep. 2017, 7, 4163. [CrossRef]

50. Mallebrera, B.; Juan-Garcia, A.; Font, G.; Ruiz, M.J. Mechanisms of beauvericin toxicity and antioxidant cellular defense. Toxicol. Lett. 2016, 246, 28-34. [CrossRef] 
51. Shang, Y.F.; Xiao, G.H.; Zheng, P.; Cen, K.; Zhan, S.; Wang, C.S. Divergent and convergent evolution of fungal pathogenicity. Genome Biol. Evol. 2016, 8, 1374-1387. [CrossRef] [PubMed]

52. Choi, J.N.; Kim, J.; Lee, M.Y.; Park, D.K.; Hong, Y.S.; Lee, C.H. Metabolomics revealed novel isoflavones and optimal cultivation time of Cordyceps militaris fermentation. J. Agric. Food Chem. 2010, 58, 4258-4267. [CrossRef] [PubMed]

53. Dubey, M.K.; Aamir, M.; Kaushik, M.S.; Khare, S.; Meena, M.; Singh, S.; Upadhyay, R.S. PR Toxin-Biosynthesis, Genetic Regulation, Toxicological Potential, Prevention and Control Measures: Overview and Challenges. Front. Pharmacol. 2018, 9, 288. [CrossRef]

54. Hidalgo, P.I.; Ullán, R.V.; Albillos, S.M.; Montero, O.; Fernández-Bodega, M.; García-Estrada, C.; Fernández-Aguado, M.; Martín, J.F. Molecular characterization of the PR-toxin gene cluster in Penicillium roqueforti and Penicillium chrysogenum: Cross talk of secondary metabolite pathways. Fungal Genet. Biol. 2014, 62, 11-24. [CrossRef] [PubMed]

55. Woloshuk, C.P.; Shim, W.B. Aflatoxins, fumonisins, and trichothecenes: A convergence of knowledge. FEMS Microbiol. Rev. 2013, 37, 94-109. [CrossRef]

56. Proctor, R.H.; McCormick, S.P.; Kim, H.S.; Cardoza, R.E.; Stanley, A.M.; Lindo, L.; Kelly, A.; Brown, D.W.; Lee, T.; Vaughan, M.M.; et al. Evolution of structural diversity of trichothecenes, a family of toxins produced by plant pathogenic and entomopathogenic fungi. PLoS Pathog. 2018, 14, e1006946. [CrossRef]

57. Chen, Y.; Kistler, H.C.; Ma, Z. Fusarium graminearum trichothecene mycotoxins: Biosynthesis, regulation, and management. Annu. Rev. Phytopathol. 2019, 57, 15-39. [CrossRef]

58. Alexander, N.J.; Proctor, R.H.; McCormick, S.P. Genes, gene clusters, and biosynthesis of trichothecenes and fumonisins in Fusarium. Toxin Rev. 2009, 28, 198-215. [CrossRef]

59. Oh, G.S.; Hong, K.H.; Oh, H.; Pae, H.O.; Kim, I.K.; Kim, N.Y.; Kwon, T.O.; Shin, M.K.; Chung, H.T. 4-Acetyl-12,13-epoxyl-9-trichothecene-3,15-diol isolated from the fruiting bodies of Isaria japonica Yasuda induces apoptosis of human leukemia cells (HL-60). Biol. Pharm Bull. 2001, 24, 785-789. [CrossRef]

60. Liu, H.; Wang, G.; Li, W.; Liu, X.; Li, E.; Yin, W.B. A highly efficient genetic system for the identification of a harzianum B biosynthetic gene cluster in Trichoderma hypoxylon. Microbiology 2018, 164, 769-778. [CrossRef]

61. Lindo, L.; McCormick, S.P.; Cardoza, R.E.; Brown, D.W.; Kim, H.S.; Alexander, N.J.; Proctor, R.H.; Gutiérrez, S. Effect of deletion of a trichothecene toxin regulatory gene on the secondary metabolism transcriptome of the saprotrophic fungus Trichoderma arundinaceum. Fungal Genet. Biol. 2018, 119, 29-46. [CrossRef] [PubMed]

62. Xu, Y.; Vinas, M.; Alsarrag, A.; Su, L.; Pfohl, K.; Rohlfs, M.; Schafer, W.; Chen, W.; Karlovsky, P. Bis-naphthopyrone pigments protect filamentous ascomycetes from a wide range of predators. Nat. Commun. 2019, 10, 3579. [CrossRef]

63. Chen, Y.X.; Feng, P.; Shang, Y.F.; Xu, Y.J.; Wang, C.S. Biosynthesis of non-melanin pigment by a divergent polyketide synthase in Metarhizium robertsii. Fungal Genet. Biol. 2015, 81, 142-149. [CrossRef] [PubMed]

64. Zeng, G.; Zhang, P.; Zhang, Q.; Zhao, H.; Li, Z.; Zhang, X.; Wang, C.; Yin, W.B.; Fang, W.G. Duplication of a $P k s$ gene cluster and subsequent functional diversification facilitate environmental adaptation in Metarhizium species. PLoS Genet. 2018, 14, e1007472. [CrossRef] [PubMed]

65. Obermaier, S.; Thiele, W.; Furtges, L.; Muller, M. Enantioselective Phenol Coupling by Laccases in the Biosynthesis of Fungal Dimeric Naphthopyrones. Angew. Chem. Int. Ed. Engl. 2019, 58, 9125-9128. [CrossRef] [PubMed]

66. Lu, S.; Sun, W.; Meng, J.; Wang, A.; Wang, X.; Tian, J.; Fu, X.; Dai, J.; Liu, Y.; Lai, D.; et al. Bioactive bis-naphtho- $\gamma$-pyrones from rice false Smut pathogen Ustilaginoidea virens. J. Agric. Food Chem. 2015, 63, 3501-3508. [CrossRef]

67. Liu, Y.; Wang, J.; Wang, W.; Zhang, H.; Zhang, X.; Han, C. The chemical constituents and pharmacological actions of Cordyceps sinensis. Evid. Based Complement. Alternat. Med. 2015, 2015, 575063.

68. Chu, Z.B.; Chang, J.; Zhu, Y.; Sun, X. Chemical Constituents of Cordyceps cicadae. Nat. Prod. Commun. 2015, 10, 2145-2146. [CrossRef]

69. Chen, P.X.; Wang, S.; Nie, S.; Marcone, M. Properties of Cordyceps sinensis: A review. J. Funct. Foods 2013, 5, 550-569. [CrossRef]

70. Jia, J.M.; Tao, H.H.; Feng, B.M. Cordyceamides A and B from the culture liquid of Cordyceps sinensis (BERK.) SACC. Chem. Pharm. Bull. 2009, 57, 99-101. [CrossRef]

71. Jia, J.M.; Ma, X.C.; Wu, C.F.; Wu, L.J.; Hu, G.S. Cordycedipeptide A, a new cyclodipeptide from the culture liquid of Cordyceps sinensis (Berk.) Sacc. Chem. Pharm. Bull. 2005, 53, 582-583. [CrossRef] [PubMed] 
72. Yang, M.L.; Kuo, P.C.; Hwang, T.L.; Wu, T.S. Anti-inflammatory principles from Cordyceps sinensis. J. Nat. Prod. 2011, 74, 1996-2000. [CrossRef] [PubMed]

73. Martel, J.; Ko, Y.F.; Liau, J.C.; Lee, C.S.; Ojcius, D.M.; Lai, H.C.; Young, J.D. Myths and realities surrounding the mysterious caterpillar fungus. Trends Biotechnol. 2017, 35, 1017-1021. [CrossRef] [PubMed]

74. Liu, G.; Cao, L.; Rao, Z.; Qiu, X.; Han, R. Identification of the genes involved in growth characters of medicinal fungus Ophiocordyceps sinensis based on Agrobacterium tumefaciens-mediated transformation. Appl. Microbiol. Biotechnol. 2020, 104, 2663-2674. [CrossRef]

75. Yan, W.J.; Li, T.H.; Lin, Q.Y.; Song, B.; Jiang, Z.D. Safety assessment of Cordyceps guangdongensis. Food Chem. Toxicol. 2010, 48, 3080-3084. [CrossRef]

76. Fung, S.Y.; Lee, S.S.; Tan, N.H.; Pailoor, J. Safety assessment of cultivated fruiting body of Ophiocordyceps sinensis evaluated through subacute toxicity in rats. J. Ethnopharmacol. 2017, 206, 236-244. [CrossRef]

(C) 2020 by the authors. Licensee MDPI, Basel, Switzerland. This article is an open access article distributed under the terms and conditions of the Creative Commons Attribution (CC BY) license (http://creativecommons.org/licenses/by/4.0/). 